\title{
Diagnóstico da Leishmaniose Visceral Canina pelas técnicas de imunoistoquímica e PCR em tecidos cutâneos em associaçáo com a RIFI e ELISA-teste
}

\author{
Canine Visceral Leishmaniasis diagnosis by immunohistochemistry and PCR \\ in skin tissues in association with RIFI and ELISA-test \\ Nina M. G. P. de Queiroz ${ }^{1}$; Juliana de Assis ${ }^{1}$; Trícia M. F. S. Oliveira² ${ }^{2}$ Rosângela Z. Machado²; \\ Cáris M. Nunes ${ }^{3}$; Wilma A. Starke-Buzetti ${ }^{1 *}$

\begin{abstract}
${ }^{1}$ Departamento de Biologia e Zootecnia, Faculdade de Engenharia de Ilha Solteira, Universidade Estadual Paulista - UNESP ${ }^{2}$ Departamento de Patologia Veterinária, Faculdade de Ciências Agrárias e Veterinárias, Universidade Estadual Paulista - UNESP

${ }^{3}$ Departamento de Apoio, Produção e Saúde Animal, Faculdade de Odontologia de Araçatuba, Curso de Medicina Veterinária, Universidade Estadual Paulista - UNESP
\end{abstract}

Recebido em 22 de Abril de 2009

Aceito em 16 de Junho de 2009

\section{Resumo}

O objetivo deste trabalho foi avaliar as técnicas de imunoistoquímica (IMIQ) e de PCR (Reação em Cadeia da Polimerase) em tecidos cutâneos para o diagnóstico da Leishmaniose Visceral Canina (LVC) e compará-los com os exames parasitológicos em tecidos corados histoquimicamente (hematoxilina-eosina, HE) e com testes sorológicos, como a Reação de Imunofluorescência Indireta (RIFI) e ensaio imunoenzimático (ELISA). Dos 34 cães naturalmente infectados, classificados em assintomáticos, oligossintomáticos e polissintomáticos, foram coletadas amostras de pele sadia ou com lesão para a realização da IMIQ, HE e PCR. Não somente peles lesionadas (56,5\%), mas também sadias $(31,8 \%)$ encontravam-se positivas pela IMIQ, confirmadas posteriormente pela PCR em $97,8 \%$ das amostras. No grupo assintomático, $87,5 \%$ estavam negativos pelos testes sorológicos, mas positivos em $50 \%$ dos casos pela IMIQ e $100 \%$ pela PCR. Entre os oligossintomáticos, $100 \%, 85,7 \%$ e 28,6\% encontravam-se positivos, respectivamente, pela PCR, sorologia e IMIQ. Os cáes polissintomáticos eram 91,7\% soropositivos e tinham parasitas na pele. Em geral, a técnica PCR teve maior positividade (100\%). A eficiência dos testes variou de acordo com a evolução da doença, demonstrando a necessidade da associaçáo de técnicas, usando-se IMIQ para confirmação da sorologia e a PCR apenas nos casos suspeitos após a IMIQ. Dessa forma, pode-se aumentar os níveis de positividade e contribuir para o controle desta zoonose.

Palavras-chave: Leishmania, cães, pele, imunoistoquímica, PCR.

\begin{abstract}
The purpose of the present study was to evaluate the immunohistochemistry (IMHC) and PCR (Polymerase Chain Reaction) tests for Canine Visceral Leishmaniasis (CVL) diagnosis and compare the results with serological tests such as the indirect fluorescence antibody test (IFAT), ELISA and a parasitological test (microscopic direct examination of the parasite stained with haematoxylin and eosin - HE). For this study, samples of healthy or lesion skin tissues were obtained from $34 \mathrm{CVL}$ naturally infected dogs classified in three groups: asymptomatic, oligosymptomatic and polisymptomatic. Not only lesion $(56.5 \%)$ but also healthy skins $(31.8 \%)$ were positives by IMHC and confirmed by PCR in $97.8 \%$ of skin samples. In asymptomatic group, $87.5 \%$ dogs were negatives by serological tests, but positives by IMHC in $50 \%$ and by PCR in $100 \%$. In oligosymptomatic group, $100 \%, 85.7 \%$ and $28.6 \%$ of dogs were positives, respectively by PCR, serological and IMHC tests. In addition, $91.7 \%$ of polisymptomatic dogs were serum positive and had intact parasites in the skin. In general, PCR showed higher positivity (100\%). The efficiency of each test varied with the evolution of the disease. IMHC may be used to confirm the results of the serology and PCR in inconclusive cases after HE and IMHC. The association of techniques proposed in this study may increase the positivity and contributed to the control of this canine disease.
\end{abstract}

Keywords: Leishmania, dogs, skin, immunohistochemistry, PCR.

\footnotetext{
*Autor para correspondência: Wilma A. Starke-Buzetti

Departamento de Biologia e Zootecnia, Universidade Estadual Paulista - UNESP,

"Júlio de Mesquita Filho", Campus de Ilha Solteira,

Passeio Monção, 226, CEP 15385-000 Ilha Solteira, SP, Brasil;

e-mail: starke@bio.feis.unesp.br
} 


\section{Introdução}

A Leishmaniose Visceral (LV) é um grave problema de saúde pública mundial, causada no Brasil por um protozoário da espécie Leishmania (L.) chagasi, transmitida por insetos vetores, que afetam homens, animais domésticos e silvestres na maioria das regióes brasileiras (BRASIL, 2003). Os cães são os reservatórios mais importantes do parasita, em área urbana, por causa da sua relaçáo de proximidade com os homens (DEANE, L. M.; DEANE, M. P., 1955). A pele dos cães tem três aspectos importantes para a LV: é a região do corpo que mais manifesta os sinais clínicos, é o local onde acontece a primeira interação entre o parasita e o sistema imune do cáo, além de ser o local onde se encontra grandes quantidades de formas amastigotas do parasita (CIARAMELLA et al., 1997).

As lesôes de pele, como a alopecia e as dermatites, são comuns na Leishmaniose Visceral Canina (LVC) (SOLANO-GALLEGO et al., 2004; ORDEIX et al., 2005). No entanto, a maioria dos cães infectados não apresenta sinal clínico (CABRAL et al., 1998) e mesmo na pele clinicamente sadia pode haver a presença de parasitas, o que alerta para a importância desses animais no ciclo de transmissão da doença (SOLANO-GALLEGO et al., 2004).

No Brasil, as estratégias de controle da doença estáo baseadas no diagnóstico e tratamento precoce de casos humanos, no controle dos vetores por meio do uso de inseticidas e na detecçáo dos cáes infectados por análises parasitológicas e sorológicas (Reaçáo de Imunofluorescência Indireta - RIFI e ensaio imunoenzimático - ELISA) com posterior eutanásia dos animais positivos (BRASIL, 2003). Enquanto os testes sorológicos apresentam mais resultados falso positivos por causa das reaçôes cruzadas com outros patógenos (BADARÓ et al., 1983; INIESTA et al., 2002), os métodos parasitológicos são mais precisos, mas também mais invasivos porque, usualmente, requerem punção de linfonodo periférico ou medula óssea.

A detecção de Leishmania sp. pela biópsia de pele é uma ferramenta alternativa para o diagnóstico. Entretanto, exames rotineiros, como a técnica de histoquímica em tecidos corados pela hematoxilina-eosina (HE), são muitas vezes inconclusivos, e uma outra técnica conhecida como imunoistoquímica (IMIQ) tem se mostrado mais eficaz para identificação do parasita, aumentando em $50 \%$ a positividade na pele (FERRER et al., 1988; TAFURI et al., 2004). Por outro lado, os métodos moleculares tem sido uma ferramenta muito útil no diagnóstico da LVC (IKONOMOPOULOS et al., 2003; XAVIER et al. 2006) em função da rapidez, sensibilidade e especificidade, particularmente para a detecção de cáes assintomáticos.

A combinação das técnicas sorológicas e moleculares tem auxiliado na demonstração de maior número de animais positivos para LVC em diferentes áreas endêmicas (GRAMICCIA; GRADONI, 2005).

Assim, o objetivo dessa pesquisa foi avaliar a utilização da PCR e da IMIQ de biópsias de pele, em comparaçáa e associaçáo com HE, ELISA e RIFI para o diagnóstico da LVC.

\section{Material e Métodos}

\section{Animais}

Trinta e quatro cáes, naturalmente infectados por Leishmania sp, com sorologia positiva (RIFI) com títulos $\leq 1: 40$, (kit Bio-Manguinhos), foram encaminhados ao Centro de Controle de Zoonoses (CCZ) de Ilha Solteira, SP, para serem eutanasiados em cumprimento ao Decreto no ${ }^{\circ} .51 .838$ do Ministério da Saúde do Brasil, de 14 de março de 1963. Esses animais (idade adulta, sem raça definida e de ambos o sexos) foram doados para a presente pesquisa e deles coletaram-se amostras de sangue, de pele sadia (sem alteraçóes macroscópicas) e de pele com lesão.

\section{Formação dos grupos de cães}

Antes e durante as necropsias, os animais foram examinados quanto aos sinais clínicos mais evidentes para LVC. Assim, os cães foram separados em três grupos: oito cães assintomáticos (sem sinais clínicos), 14 cães oligossintomáticos (até três sinais clínicos ou comprometimento de até três órgãos) e 12 cães polissintomáticos (mais de três sinais clínicos ou com mais de três órgãos acometidos). Adicionalmente, durante as necropsias, fragmentos de fígado, baço e linfonodo foram coletados para realização de in print de órgáos para pesquisa de formas amastigotas de Leishmania sp., que confirmou a Leishmaniose Visceral.

\section{Exames parasitológicos (HE e IMIQ)}

No grupo dos cães oligossintomáticos, as amostras de pele foram coletadas de áreas com lesão e sem lesão macroscópica do mesmo câo, na maioria deles. Dessa forma, coletaram-se 22 amostras de pele sadia (oito cães assintomáticos e 14 cães oligossintomáticos) e 23 de pele com lesão (12 cáes polissintomáticos e 11 oligossintomáticos). As amostras de pele com lesão foram coletadas principalmente dos locais onde as lesóes estavam mais evidentes e, as peles sadias, preferencialmente do focinho e ponta da orelha. Essas amostras foram, inicialmente, fixadas em formalina tamponada a 10\%, lavadas três vezes em álcool $70^{\circ} \mathrm{C}$ e deixadas no álcool até a utilização pelas técnicas histoquímica e imunoistoquímica.

$\mathrm{Na}$ técnica de histoquímica (HE), os tecidos fixados foram processados e incluídos em parafina. Três secções de cada amostra ( $5 \mu \mathrm{m}$ de espessura) foram montadas em lâminas e coradas com hematoxilina e eosina, para pesquisar a presença de formas amastigotas de Leishmania, sob microscopia óptica de luz branca, com aumento variando de 400 a 1.000 vezes.

Para a técnica de imunoistoquímica (IMIQ), seguiram-se os procedimentos indicados por Tafuri et al. (2004), utilizando-se como anticorpo primário o soro hiperimune de cáes naturalmente infectados com $L$. $(L$.) chagasi (RIFI com título = 1:2.560) e, como anticorpo secundário, o anti-IgG de coelho. Como modificaçáo dessa técnica, utilizou-se o mesmo anticorpo secundário, porém conjugado à biotina ao invés da peroxidase (Vector Laboratories, Inc., Burlingame, CA, USA). Para detecção da reação imunológica, aplicou-se o complexo "Avidin-Biotin Peroxidase" (Vectstain ABC Kit; Vector Laboratories) e o substrato cromógeno específico para peroxidase (Substrato "New Red"- Vector Laboratories). O controle negativo foi realizado sem a adiçáo do anticorpo primário ou do secundário. Duas lâminas com duas secçôes teciduais para cada amostra cutânea foram analisadas.

\section{Exames sorológicos (ELISA e RIFI)}

Antes da eutanásia dos cáes, amostras de sangue foram coletadas por venopunçáo cefálica e armazenadas em tubos sem 
EDTA, para obtenção do soro e posterior realização dos exames sorológicos. Adicionalmente ao exame realizado, utilizando-se o kit Bio-Manguinhos nos laboratórios autorizados pela Secretaria da Saúde, realizou-se os testes sorológicos RIFI e ELISA indireto de acordo com a técnica descrita por Oliveira et al. (2008) para L. (L.) chagasi. Foram consideradas positivas as reaçóes fluorescentes em soros com diluição >1:40 e nível ELISA (NE) >3.

\section{Técnica da Reação em Cadeia pela Polimerase (PCR)}

No momento da necropsia, as amostras de pele sadia e com lesão foram coletadas assepticamente e colocadas em nitrogênio líquido antes de serem armazenadas em freezer a $-70{ }^{\circ} \mathrm{C}$, até a extração do DNA. Este foi extraído de $30 \mathrm{mg}$ de tecido, utilizando-se o "Kit QIAamp Blood and Tissue" (Qiagen, Santa Clarita, CA, USA) para um volume final de $100 \mu \mathrm{L}$.

A amplificação de fragmentos de DNA de 120 pares de base (pb) conservados do minicírculo do cinetoplasto, foi realizada pela PCR, utilizando-se o par de oligonucleotídeos para o gênero Leishmania sp. descrito por Rodgers et al. (1990): 13A 5'-dGTG GGG GAG GGG CGT TCT-3' e 13B 5'-dATT TTA CAC CAA CCC CCA GTT-3' e, como enzima da reação, a polimerase Platinum ${ }^{\oplus}$ Taq (Invitrogen-Carlsbad-Califórnia). Os controles positivos utilizados na reação de PCR foram DNA de Leishmania sp extraído de pele de cães naturalmente infectados, segundo Nunes et al. (2007). Os controles negativos foram DNA de pele de cães sadios de área não endêmica para LVC, sabidamente negativos pelo exame parasitológico, sorológico e PCR. Além disso, uma mistura contendo $22,5 \mu \mathrm{L}$ dos reagentes, sem DNA, foi utilizada para o controle da reação (NO). A verificação da amplificação dos fragmentos de DNA de $120 \mathrm{pb}$ foi feita com $8 \mu \mathrm{L}$ do produto de PCR por eletroforese em gel de poliacrilamida a $8 \%$, corado com nitrato de prata.

\section{Análise estatística}

Para avaliar a concordância entre os diferentes métodos de diagnóstico, calculou-se o índice Kappa ( $)$ de concordância (intervalo de confiança 95\%), usando-se o programa Biostat, versão 4.0 (AYRES et al., 2005), sendo $\kappa<0,4$ aceito como concordância fraca, $0,4<\kappa<0,7$ como boa e $\kappa>0,7$ como ótima.

\section{Resultados e Discussão}

Após a realização dos exames para observação dos sinais clínicos, oito cães foram classificados como assintomáticos (23,5\%), 14 oligossintomáticos $(41,2 \%)$ e 12 polissintomáticos $(35,3 \%)$. As principais alterações clínicas observadas nos cães oligossintomáticos foram lesôes gerais de pele e mucosas pálidas. Já os cães polissintomáticos encontravam-se bastante comprometidos, pois além das alteraçóes gerais de pele, os mesmos apresentavam esplenomegalia, fígado ictérico, emagrecimento, linfonodos hipertróficos e onicogrifose. As alteraçóes cutâneas mais observadas nesses cães foram as dermatites, caracterizadas por: hiperqueratose, principalmente nas juntas dos membros anteriores e posteriores e nas patas; alopecia periocular; lesóes na ponta dos pavilhóes auriculares; descamação; hipotricose e crostas em diferentes partes do corpo.

Nos cães assintomáticos, embora as amostras séricas de 87,5\% (7/8) tenham sido negativas nos testes sorológicos, os exames $\mathrm{HE}$ e IMIQ revelaram positividade em 50\% dos animais, com carga parasitária variando de moderada a intensa, e a PCR revelou positividade de $100 \%$ nas amostras de pele sadia (Tabela 1). De forma semelhante, Abranches et al. (1991) demonstraram que os cães naturalmente infectados com $L$. infantum apresentaram grande quantidade de parasitas na pele independentemente da presença de lesôes. A baixa detecção de anticorpos nos animais assintomáticos poderia indicar que estivessem no início da infecção antes da soroconversão, mas já possuindo parasitas na pele. Outros estudos mostraram uma grande variaçáo no período de soroconversão em cães naturalmente infectados de 94 dias até um ano (QUINNELL et al., 1997, 2003; SOLANO-GALLEGO et al.; 2005).

Relativo aos cães oligossintomáticos, $85,7 \%$ foram positivos pelos testes sorológicos (RIFI ou ELISA) e apenas 28,6\% (4/14) desses animais foram simultaneamente positivos nos testes sorológicos e parasitológicos (IMIQ ou HE), com carga parasitária de moderada a intensa, incluindo três cães que tiveram os mais altos títulos de anticorpos e forte parasitismo, mesmo sem lesão nas amostras de pele. Por outro lado, 66,6\% dos cães soropositivos (particularmente pelo ELISA) não apresentaram amastigotas nas amostras de pele (HE e IMIQ). A PCR revelou a presença do DNA de Leishmania sp. em 97,8\% das amostras de pele dos animais oligossintomáticos (Tabela 2). Courtenay et al. (2002) observaram correlação positiva entre grau parasitário, infectividade, nível de anticorpos anti-Leishmania sp., detecção de DNA do parasita por PCR e presença de sinais clínicos. Dessa forma, quanto mais sintomático for o cão, mais fácil

Tabela 1. Número $(\mathrm{N})$ e porcentagens (\%) de cães positivos para Leishmaniose Visceral pelos testes sorológicos (RIFI e ELISA), parasitológicos (HE e IMIQ) e molecular (PCR), em amostras de peles sadias e com lesão de cães naturalmente infectados e classificados em assintomáticos $(\mathrm{A})$, oligossintomáticos $(\mathrm{O})$ e polissintomáticos $(\mathrm{P})$. Ilha Solteira, 2008.

\begin{tabular}{|c|c|c|c|c|c|c|}
\hline \multirow{2}{*}{$\begin{array}{c}\text { Grupos } \\
(\mathrm{N})\end{array}$} & \multicolumn{6}{|c|}{ Exames sorológicos e de pesquisa parasitária - N (\%) } \\
\hline & ELISA & RIFI & $\begin{array}{l}\text { RIFI/ } \\
\text { ELISA }\end{array}$ & HE & IMIQ & PCR \\
\hline $\begin{array}{l}\text { A } \\
(8)\end{array}$ & $\begin{array}{c}1 \\
(12,5)\end{array}$ & $\begin{array}{c}1 \\
(12,5)\end{array}$ & $\begin{array}{c}1 \\
(12,5)\end{array}$ & $\begin{array}{c}3 \\
(37,5)\end{array}$ & $\begin{array}{c}4 \\
(50,0)\end{array}$ & $\begin{array}{c}8 \\
(100,0)\end{array}$ \\
\hline $\begin{array}{c}\mathrm{O} \\
(14)\end{array}$ & $\begin{array}{c}11 \\
(78,6)\end{array}$ & $\begin{array}{c}8 \\
(57,1)\end{array}$ & $\begin{array}{c}12 \\
(85,7)\end{array}$ & $\begin{array}{c}3 \\
(21,4)\end{array}$ & $\begin{array}{c}4 \\
(28,6)\end{array}$ & $\begin{array}{c}14 \\
(100,0)\end{array}$ \\
\hline $\begin{array}{c}\mathrm{P} \\
(12)\end{array}$ & $\begin{array}{c}10 \\
(83,3)\end{array}$ & $\begin{array}{c}10 \\
(83,3)\end{array}$ & $\begin{array}{c}11 \\
(91,7)\end{array}$ & $\begin{array}{c}9 \\
(75,0)\end{array}$ & $\begin{array}{c}11 \\
(91,7)\end{array}$ & $\begin{array}{c}12 \\
(100,0)\end{array}$ \\
\hline $\begin{array}{l}\text { Total } \\
(34)\end{array}$ & $\begin{array}{c}22 \\
(64,7)\end{array}$ & $\begin{array}{c}19 \\
(55,9)\end{array}$ & $\begin{array}{c}24 \\
(70,6)\end{array}$ & $\begin{array}{c}15 \\
(44,1)\end{array}$ & $\begin{array}{c}19 \\
(55,9)\end{array}$ & $\begin{array}{c}34 \\
(100,0)\end{array}$ \\
\hline
\end{tabular}

ELISA: ensaio imunoenzimático; RIFI: reação de imunofluorescência indireta; HE: técnica histoquímica de hematoxilina e eosina; IMIQ: técnica de imunoistoquímica; PCR: reação em cadeia da polimerase. 
o diagnóstico pelas diferentes técnicas disponíveis e o inverso também é verdadeiro.

No grupo polissintomático, a positividade variou de acordo com o método de diagnóstico utilizado; aumentando de 75,0\% pela $\mathrm{HE}$ (intensidade parasitária fraca a intensa) para 91,7\%, quando foram empregados tanto a IMIQ quanto a sorologia, e atingindo $100 \%$ quando avaliados pela PCR (Tabela 1).

A presença de formas amastigotas de Leishmania sp. foi observada pela IMIQ em 56,5\% das amostras de pele com lesão e em apenas $31,8 \%$ das peles clinicamente sadias, sendo essa positividade aumentada pela PCR nas amostras de pele com lesão $(95,6 \%)$ e, principalmente, naquelas de pele sadia (100\%) (Tabela 2). Trabalhos anteriores também revelaram a presença de parasitas em peles clinicamente sadias, independentemente da manifestação clínica dos cães, através da IMIQ (PAPADOGIANNAKIS et al., 2005; SOLANO-GALLEGO et al., 2004) e da PCR (SOLANO-GALLEGO et al., 2004).

Tabela 2. Números (N) e porcentagens (\%) de amostras cutâneas (sadias ou com lesão) positivas pela presença de formas amastigotas de Leishmania sp. pelos exames parasitológicos histoquímicos (HE), imunoistoquímica (IMIQ) e DNA pela PCR em cães com Leishmaniose Visceral. Ilha Solteira, 2008.

\begin{tabular}{lccc}
\hline Classificaçáo & \multicolumn{4}{c}{ Exames parasitológicos e molecular - N (\%) } \\
\cline { 2 - 4 } das peles (N) & HE & IMIQ & PCR \\
\hline Sadia $(22)$ & $5(22,7)$ & $7(31,8)$ & $22(100,0)$ \\
Lesão $(23)$ & $11(47,8)$ & $13(56,5)$ & $22(95,6)$ \\
\hline Total $(45)$ & $16(35,6)$ & $20(44,4)$ & $44(97,8)$ \\
\hline
\end{tabular}

HE: técnica histoquímica de hematoxilina e eosina; IMIQ: técnica de imunoistoquímica; PCR: reaçáo em cadeia da polimerase.
Por meio da técnica HE, 32,4\% (11/34) cães, principalmente do grupo oligossintomático, foram considerados suspeitos devido à dificuldade de visualização das formas amastigotas. Três desses cães, posteriormente, tiveram a positividade confirmada pela IMIQ e 11 pela PCR. Bourdoiseau et al. (1997) também relataram que, embora HE fosse específica e usada como avaliação de rotina, havia certa dificuldade para visualização das amastigotas e, algumas vezes, os exames eram inconclusivos. A positividade pela HE foi sempre menor do que pela IMIQ neste estudo (Tabela 1).

A técnica imunoistoquímica tem sido empregada para detecção de formas amastigotas de Leishmania sp. (FERRER et al., 1988; BOURDOISEAU et al., 1997; SOLANO-GALLEGO et al., 2004; TAFURI et al., 2004; XAVIER et al., 2006), verificando-se maior sensibilidade em relação à técnica $\mathrm{HE}$, mas variando de acordo com os sinais clínicos, entre 92,7, 76,0 e 100,0\%, respectivamente, para cães sintomáticos, oligossintomáticos e assintomáticos (MOREIRA et al., 2007). O método IMIQ permite, portanto, uma melhor visualização do parasita, pois possibilita um alto grau de contraste entre os parasitas e o tecido do hospedeiro, sendo possível o diagnóstico mais preciso da LVC (ORDEIX et al., 2005). Contudo, a IMIQ tem sido considerada por alguns autores como menos sensível do que a PCR (ROURA et al., 1999; XAVIER et al., 2006), pois, segundo Ordeix et al. (2005), a técnica PCR é sensível o suficiente para detectar um número muito baixo de parasitas nas amostras de tecidos cutâneos. Em concordância, neste trabalho, a maior positividade foi obtida quando se utilizou a PCR, que foi de $100 \%$, independentemente dos sinais clínicos, da sorologia e da presença de parasitas na pele (Tabela 1).

Para o diagnóstico da LVC, as técnicas sorológicas são consideradas rápidas e práticas, mas com sensibilidade variável e especificidade baixa (BADARÓ et al., 1983; INIESTA et al.,

Tabela 3. Análise comparativa do número (nc) e porcentagens (\%) de concordância e índice Kappa ( $\kappa)$ entre as técnicas imunoistoquímica $(I M I Q) \times$ ELISA, IMIQ $\times$ RIFI, ELISA $\times$ RIFI, PCR $\times$ IMIQ, PCR $\times$ ELSA e PCR $\times$ RIFI para diagnóstico de Leishmaniose Visceral em cães naturalmente infectados e classificados em assintomáticos $(\mathrm{A})$, oligossintomáticos $(\mathrm{O})$ e polissintomáticos $(\mathrm{P})$.

\begin{tabular}{|c|c|c|c|c|}
\hline \multirow[b]{2}{*}{$\begin{array}{c}\text { Comparaçáo entre os } \\
\text { exames/nc (\%) }\end{array}$} & \multicolumn{4}{|c|}{ Grupos } \\
\hline & $\begin{array}{c}A \\
(N=8)\end{array}$ & $\begin{array}{c}\mathrm{O} \\
(\mathrm{N}=14)\end{array}$ & $\begin{array}{c}P \\
(N=12)\end{array}$ & $\begin{array}{c}\text { Total } \\
(\mathrm{N}=34)\end{array}$ \\
\hline IMIQ $\times$ ELISA & $\begin{array}{l}5(62,5) \\
\kappa=0,25\end{array}$ & $\begin{array}{l}7(50,0) \\
\kappa=0,20\end{array}$ & $\begin{array}{l}11(91,7) \\
\kappa=0,62^{*}\end{array}$ & $\begin{array}{r}23(67,6) \\
\kappa=0,32\end{array}$ \\
\hline IMIQ × RIFI & $\begin{array}{l}5(62,5) \\
\kappa=0,25\end{array}$ & $\begin{aligned} 10 & (71,4) \\
\kappa & =0,46^{*}\end{aligned}$ & $\begin{aligned} 11 & (91,8) \\
\kappa & =0,62^{*}\end{aligned}$ & $\begin{array}{r}26(76,5) \\
\kappa=0,52^{*}\end{array}$ \\
\hline ELISA $\times$ RIFI & $\begin{array}{l}8(100,0) \\
\kappa=1,0\end{array}$ & $\begin{array}{l}9(64,3) \\
\kappa=0,22\end{array}$ & $\begin{array}{r}10(83,3) \\
\kappa=0,40\end{array}$ & $\begin{aligned} 27 & (79,4) \\
\kappa & =0,57^{*}\end{aligned}$ \\
\hline PCR × IMIQ & $\begin{array}{c}4(50,0) \\
* *\end{array}$ & $\begin{array}{l}4(28,6) \\
* *\end{array}$ & $11 \underset{* *}{(91,6)}$ & $19 \underset{* *}{(55,9)}$ \\
\hline PCR $\times$ ELISA & $\begin{array}{c}(12,5) \\
* *\end{array}$ & $\begin{array}{c}11(78,6) \\
* *\end{array}$ & $10 \underset{* *}{(83,3)}$ & $\begin{array}{c}22(64,7) \\
* *\end{array}$ \\
\hline PCR $\times$ RIFI & $\underbrace{(12,5)}_{* *}$ & $\begin{array}{c}8(57,1) \\
* *\end{array}$ & $\begin{array}{c}10(83,3) \\
* *\end{array}$ & $\begin{array}{c}19(55,8) \\
* *\end{array}$ \\
\hline
\end{tabular}

*Estatisticamente significativo $(\mathrm{p} \leq 0,05)$. Intervalo de confiança $=95 \%$.

**Năo foi possível fazer o teste para índice Kappa devido à positividade total da PCR.

ELISA: ensaio imunoenzimático; RIFI: reação de imunofluorescência indireta; HE: técnica histoquímica de hematoxilina e eosina; IMIQ: técnica de imunoistoquímica; PCR: reação em cadeia da polimerase; N: número de animais por grupo. 
2002). Neste estudo, os exames sorológicos apresentaram baixa positividade no grupo dos assintomáticos, sendo de $12,5 \%$ tanto pelo ELISA quanto pela RIFI, e valores maiores nos oligossintomáticos $($ ELISA $=78,6 \%$ e RIFI $=57,1 \%)$ e polissintomáticos, que tiveram $83,3 \%$ de positividade para ambos os testes. Em geral, verificou-se positividade de $64,7 \%$ pelo ELISA, seguido pela RIFI e IMIQ $(55,9 \%)$ e pela $\mathrm{HE}(44,1 \%)$ (Tabela 1$)$.

Quando a análise comparativa foi realizada entre RIFI e ELISA, verificou-se que a concordância foi de $100 \%$ nos animais assintomáticos, mas menor nos animais oligossintomáticos e polissintomáticos. Zanette (2006) verificou resultados semelhantes, validando a comprovação de que esses dois testes podem apresentar, em alguns casos, resultados divergentes no diagnóstico da LVC. Quando se comparou os testes sorológicos (ELISA ou RIFI) com a IMIQ, verificou-se uma associação fraca entre IMIQ $\times$ ELISA $($ Kappa $=0,32)$ e boa entre IMIQ $\times$ RIFI $($ Kappa =0,52), embora ambas as associaçóes de testes tenham melhorado o índice de concordância nos animais polissintomáticos (Tabela 3). Como nenhum desses testes aproximou-se do nível de concordância excelente, fica difícil a replicação entre eles no diagnóstico da LVC, pois depende muito do estado evolutivo da doença e da resposta imune do hospedeiro.

Dessa forma, cabe salientar que a maioria dos animais com títulos altos de anticorpos, pela RIFI ou ELISA, apresentou também formas amastigotas nas amostras de pele. Altos títulos de anticorpos pela RIFI, assim como pelo ELISA, foram detectados no grupo dos polissintomáticos, em concordância com os dados de Reis et al. (2006). Porém, quando não houve concordância entre ambos os testes sorológicos e quando os títulos de anticorpos foram baixos, as formas amastigotas não foram detectadas na pele utilizando-se os testes parasitológicos (HE e IMIQ), sendo positivos apenas pela PCR, fato que aconteceu particularmente nos cáes oligossintomáticos. Concordantemente, Courtenay et al. (2002) observaram que, antes da soroconversão, os cães não apresentavam em suas peles número suficiente de formas amastigotas para infectar os flebotomíneos, e a detecção do parasita, nessa fase, só foi possível pela PCR.
A PCR foi também comparada com os testes sorológicos e com a IMIQ. Com exceção dos animais polissintomáticos, as análises comparativas revelaram baixa concordância entre os testes (Tabela 3), dados esses semelhantes aos de Nunes et al. (2007). Esse resultado não é inesperado, pois essa técnica molecular foi a que apresentou maior positividade (100,0\%) entre os cães, detectando DNA do parasita em todas as amostras de tecido cutâneo dos três grupos, tanto nas peles sadias quanto nas lesionadas, com exceção de uma única amostra de pele com lesão, negativa, de um animal oligossintomático. Por outro lado, esse cáo apresentou DNA do parasita em sua pele sadia. Em concordância, Solano-Gallego et al. (2004) demonstraram que nas peles dos cães assintomáticos sem lesóes macroscópicas ou amastigotas a PCR era positiva. Essa observação indica que o número de parasitas devia ser muito baixo e de difícil identificação, mesmo na técnica imunoistoquímica.

As provas sorológicas e parasitológicas, quando testadas isoladamente, não apresentaram o mesmo grau de eficiência nos cães pertencentes aos três grupos clínicos analisados. Assim, no grupo dos cães assintomáticos, os testes sorológicos não foram boas opçóes para o diagnóstico da LVC, sendo preferível o uso de métodos parasitológicos e da PCR antes da soroconversão e o aparecimento dos sintomas, como sugerido também por Quinnell et al. (2001). Da mesma forma, os exames parasitológicos (IMIQ e HE) foram pouco eficientes em cães oligossintomáticos. No entanto, para os animais do grupo polissintomático, todos os testes utilizados foram eficientes. Dentre todos os testes, a PCR apresentou maior positividade nos três grupos de cães, tanto em amostras de pele com lesão quanto nas sadias, independentemente dos sinais clínicos dos animais ou dos resultados dos exames sorológicos e parasitológicos.

No presente trabalho, observou-se que quando o método sorológico era associado com a imunoistoquímica a positividade aumentava para 79,4\% e com a PCR esse resultado alcançava $100,0 \%$. Corroborando com o trabalho de Gramiccia; Gradoni (2005), onde verificaram que a combinação das técnicas sorológicas e moleculares aumentava a detecção da infecção canina em

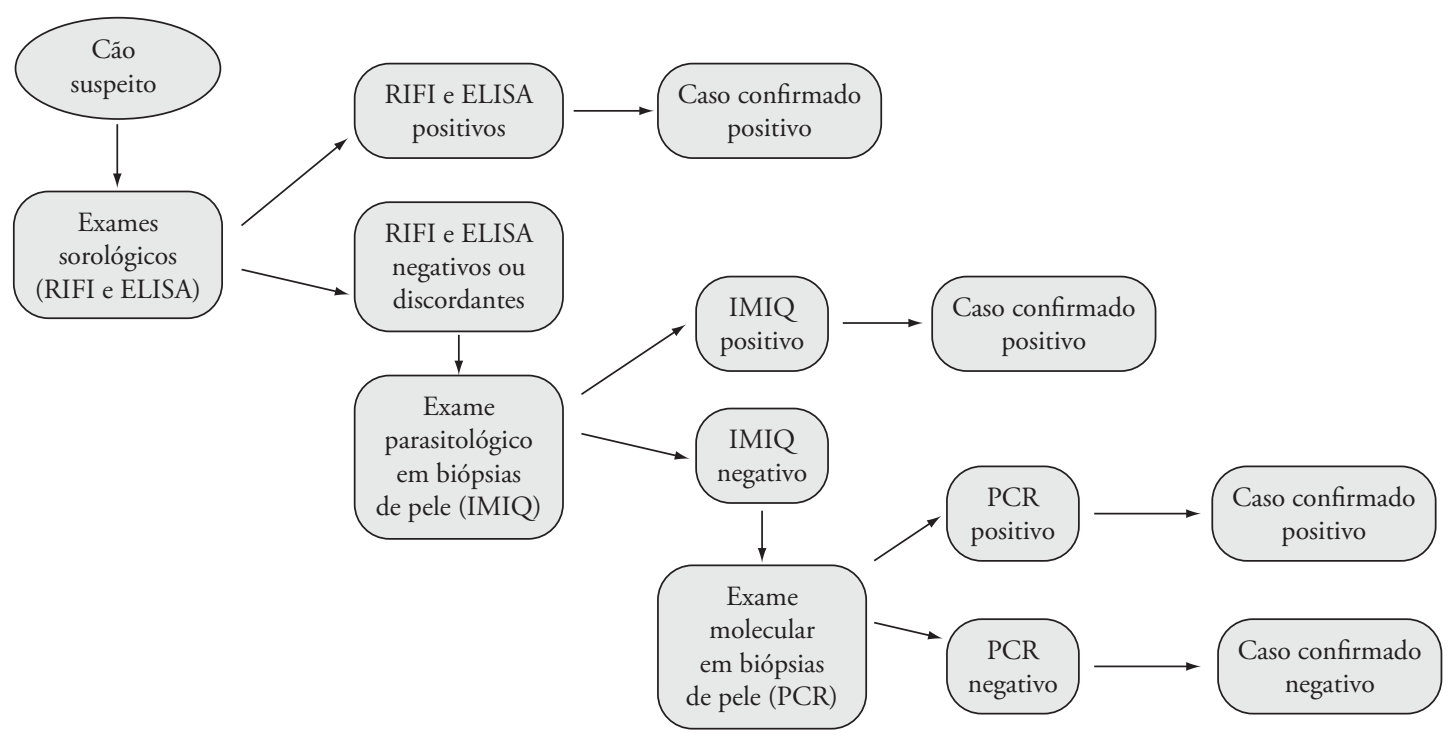

Figura 1. Diagrama para orientação do diagnóstico de Leishmaniose Visceral Canina. 
diferentes áreas endêmicas. Cabe salientar que a técnica de PCR, a qual se tem aprimorado e difundido, é comprovadamente mais sensível e poderia ser a técnica de eleição para o diagnóstico da LVC. No entanto, esta técnica ainda é onerosa, não faz parte da rotina de muitos laboratórios e também não está padronizada pelo Ministério da Saúde no Brasil.

A análise dos dados sugere a necessidade da associação de técnicas, pois os resultados dos diagnósticos variam com a evolução da doença em cada animal. Dessa forma, para confirmação da sorologia, que é mais rápida e prática nos casos de inquéritos epidemiológicos, sugere-se a IMIQ dentre os métodos parasitológicos, por ser mais sensível que a HE e mais viável que a PCR, ficando essa técnica molecular restrita apenas à confirmação dos casos ainda suspeitos após a IMIQ. Mediante o exposto nesta discussão, propóe-se a seqüência de procedimentos diagnósticos da Figura 1, que demonstra a associação de técnicas para aumentar os níveis de positividade e contribuir no controle da doença.

\section{Agradecimentos}

Os autores agradecem à FAPESP pelo apoio financeiro e ao Centro de Controle de Zoonoses de Ilha Solteira - SP pela doação dos animais.

\section{Referências}

ABRANCHES, P. et al. Canine Leishmaniasis: pathological and ecological factors influencing transmission of infection. Journal of Parasitology, v. 77, n. 4, p. 557-561, 1991.

AYRES, M. et al. BioEstat - Aplicaçóes estatísticas nas áreas das ciências bio-médicas. Versão 4.0. Belém, Pará, Brasil: Instituto de desenvolvimento sustentável Mamirauá, 2005.

BADARÓ, R.; REED, S. G.; CARVALHO, E. M. Immunofluorescent antibody test in American visceral leishmaniasis: sensitivity and specificity of different morphological forms of two Leishmania species. The American Journal of Tropical Medicine and Hygiene, v. 32, n. 3 , p. 480-84, 1983.

BOURDOISEAU, G.; MARCHAL, T.; MAGNOL, J. P. Immunohistochemical detection of Leismania infantum in formalin-fixed, paraffin-embedded sections of canine skin and lymph nodes. Journal Veterinary Diagnostic Investigation, v. 2, n. 9, p. 439-440, 1997.

BRASIL. Ministério da Saúde. Manual de vigilância e controle da Leishmaniose Visceral: normas e manuais técnicos. Brasília: Ministério da Saúde, 2003. 120p.

CABRAL, M. et al. The immunology of canine leishmaniosis: strong evidence for a developing disease spectrum from asymptomatic dogs. Veterinary Parasitology, v. 76, n. 3, p. 173-180, 1998.

CIARAMELLA, P. et al. A retrospective clinical study of canine leishmaniasis in 150 dogs naturally infected by Leishmania infantum. Veterinary Record, v. 141, n. 21, p. 539-543, 1997.

COURTENAY, O. et al. Infectiouness in a cohort of brazilian dogs: why culling fails to control visceral leishmaniasis in áreas of high transmission. Journal of Infectious Diseases, v. 186, n. 9, p. 1314-1320, 2002.

DEANE, L. M.; DEANE, M. P. Observaçôes preliminares sobre a importância comparativa do homem, do cão e da raposa (Lycalopes vetulus) como reservatórios da Leishmania donovani em área endêmica da calazar, no Ceará. O Hospital, v. 48, p. 61-76, 1955.
FERRER, L.; RABANAL, R. M.; DOMINGO, M. Identification of Leishmania donovani amastigotes in canine tissues by immuneperoxidase staining. Research Veterinary Science, v. 44, n. 2, p. 194-196, 1988.

GRAMICCIA, M.; GRADONI, L. The current status of zoonotic leishmaniasis and approaches to disease control. International Journal for Parasitology, v. 35, n. 11-12, p. 1169-1180, 2005.

IKONOMOPOULOS, J. et al. Molecular diagnosis of leishmaniosis in dogs: comparative application of traditional diagnostic methods and the proposed assay on clinical samples. Veterinary Parasitology, v. 113, n. 2, p. 99-113, 2003.

INIESTA, L. et al. Diagnostic techniques to detect cryptic leishmaniasis in dogs. Clinical and Diagnostic Laboratory Immunology, v. 9, n. 5, p. 1137-1141, 2002.

MOREIRA, M. A. B. et al. Comparison of parasitological, immunological and molecular methods for the diagnosis of Leishmaniasis in dogs with different clinical signs. Veterinary Parasitology, v. 145, n. 3-4, p. 245-252, 2007.

NUNES, C. M. et al. Avaliação da reaçáo em cadeia pela polimerase para diagnóstico da leishmaniose visceral em sangue de cães. Revista Brasileira de Parasitologia Veterinária, v. 16, n. 1, p. 5-9, 2007.

OLIVEIRA, T. M. F. S. et al. A study of cross-reactivity in serum samples from dogs positive for Leishmania sp., Babesia canis and Ehrlichia canis in enzyme-linked immunosorbent assay and indirect fluorescent antibody test. Revista Brasileira Parasitologia Veterinária, v. 17, n. 1, p. 7-11, 2008.

ORDEIX, L. et al. Papular dermatitis due to Leishmania spp. Infection in dogs with parasite-specific cellular immune response. Veterinary Dermatology, v. 16, p. 187-191, 2005.

PAPADOGIANNAKIS, E. I.; KOUTINAS, A. F; ARIDOMICHELAKIS, M. N. Cellular immunophenotyping of exfoliative dermatitis in canine leishmaniosis (Leishmania infantum). Veterinary Immunology and Immunopathology, v. 104, n. 3-4, p. 227-237, 2005.

QUINNEL, R. J. et al. Detection of Leishmania infantum by PCR, serology and cellular immune response in a cohort study of Brazilian dogs. Parasitology, v. 122, n. 3, p. 253-261, 2001.

QUINELL, R. J. et al. The epidemiology of canine leishmaniasis: transmission rates estimated from a cohort study in amazonian Brazil. Parasitology, v. 115, n. 2, p. 143-156, 1997.

QUINNELL, R. J. et al. IgG subclass responses in a longitudinal study of canine visceral leishmaniasis. Veterinary Immunology and Immunopathology, v. 91, n. 3-4, p. 161-168, 2003.

REIS, A. B. et al. Parasite density and impaired biochemical hematological status are associated with severe clinical aspects of canine visceral leishmaniasis. Research Veterinary Science, v. 81, n. 1, p. 68-75, 2006.

RODGERS, M. R.; POPPER, S. J.; WIRTH, D. F. Amplification of kinetoplast DNA as tool in the detection and diagnosis of Leishmania. Experimental Parasitology, v. 71, n. 3, p. 267-275, 1990.

ROURA, X.; SANCHEZ, A.; FERRER, L. Diagnosis of canine leishmaniasis by a polymerase chain reaction technique. Veterinary Record, v. 144, n. 10, p. 262-264, 1999.

SANTA ROSA, I. C. A.; OLIVEIRA, I. C. S. Leishmaniose visceral: breve revisão sobre uma zoonose reemergente. Clínica Veterinária, v. 2, n. 11, p. 24-28, 1997. 
SOLANO-GALLEGO, L. et al. Histological and Immunoistochemical Study of Clinically Normal Skin of Leishmania infantum-infected Dogs. Journal Comparative of Pathology, v. 130, n. 1, p. 7-12, 2004.

SOLANO-GALLEGO, S. et al. Longitudinal study of dogs living in an area of Spain highly endemic for leishmaniasis by serologic analysis and the leishmanin skin test. American Journal of Tropical Medicine and Hygiene, v. 72, n. 6, p. 815-818, 2005.

TAFURI, W. L. et al. An alternative immunohistochemical method for detecting Leishmania amastigotes in parafiin-embedded canine tissues. Journal of Immunological Methods, v. 292, n. 1-2, p. 17-23, 2004.
XAVIER, S. C. et al. Comparison of paraffin - embedded skin biopsies from different anatomical regions as sampling methods for detection of Leishmania infection in dog using histological, immunohistochemical and PCR methods. BMC Veterinary Research, v. 2, n. 17, p. 1-7, 2006.

ZANETTE, M. F. Comparaçáo entre os métodos de ELISA, imunofluorescência indireta e imunocromatografia para o diagnóstico da leishmaniose visceral canina. 2006. 75 f. Dissertação (Mestrado em Ciência Animal) - Faculdade de Odontologia e Curso de Medicina Veterinária, Universidade Estadual Paulista (UNESP), Araçatuba, 2006. 